\title{
The Sacredness of Remembering and Re-storying

\author{
Christina Romero-Ivanova
}

\begin{abstract}
This article discusses findings from a qualitative research study which focused on how women from diverse backgrounds used storying as a space to make sense of life experiences that had highly impacted their lives. This article explores how women's stories mediate their experiences of being temporarily silenced, how they resisted others' silencing over their own viewpoints, and how their storying mediates different ways of "talking back" through storywriting in letters and journals and story-living through an intentional practice of wearing an artifact of trauma. Multiple interviews were used as the primary data sources, and through these the participants' stories emerged. Intersections of gender, race, religion, and socioeconomic status in the participants' stories were analyzed, and the categories of silencing, resistance/talking back, and resilience developed. Findings included the participants' abilities to navigate issues related to others' forced perspectives on their bodies as a social and political space (Pitts, 2003; Woods, 2012).
\end{abstract}

Keywords: narrative, silencing, resistance, talking back, resilience, intersectionality

\section{Introduction}

This article focuses on three women participants' storying, from a larger narrative inquiry study which was conducted to understand how women from diverse backgrounds used storying as a space in which to make sense of their crucial experiences. Narrative methods were employed to glean detailed accounts of three women's storied experiences. Eventually, as the three women's stories emerged, the inquiry delved into each woman's different modes of storying (orally relating their experiences, journaling, letter-writing, and collage-making), to attend closely to their use of language and to triangulate the meanings that emerged.

\section{Background}

Individuals' everyday literacies have been widely studied from various perspectives (Barton \& Hamilton, 2000; Gonzalez et al., 2005; Heath, 1983; Jones, 2006; Scribner \& Cole, 1978), and the research has provided insight into the complexities of individuals' layered backgrounds and experien-

Contact: Christina Romero-Ivanova, Indiana University Kokomo, USA.

E-mail: civanova@iuk.edu

(C) 2020 IJLCLE and Christina Romero-Ivanova 
ces. Increasingly, individuals' narratives are being acknowledged as important ways of knowing and have stimulated a line of inquiry specifically into Women's Ways of Knowing (WWK) (Bartky, 1996; Belenky et al., 1986; Bye, 2005; Daniell, 2003). As Belenky et al have characterized this perspective, the aim is "to bring attention to the missing voices of women in our theories of how people know and learn" (p. 3) and create a necessary space for women to be able to talk about their own knowledge gleaned from their experiences.

\section{Gaps in Knowledge}

WWK (Bartky, 1996; Belenky et al., 1986) considers the complexity of individuals' knowledge, and their storying of that knowledge, but it has not emphasized women's storying as an embedded literacy practice. As Pahl and Rowsell (2010) note, "some stories are artifacts, told and retold over and over" (p. 11). Youths' and teenagers' stories have been acknowledged, as well as their connections to embedded artifacts and literacy practices (Pahl \& Rowsell, 2010). However, the space that acknowledges women's storying of their own lived experiences as significant literacy practices has not been significantly established. A space for considering women's storying of their experiences, and a recognition of their storyings as literacy practices, needs to be further developed.

Storying, as Pahl and Rowsell (2010) state, is connected to literacy: "Talk and story can also be connected to literacy. From small stories, bigger stories can grow" (p. 40). From storying, other literacy practices, such as writing, emerge. The widening of a space that considers individuals' intimate literacy practices, such as storying crucial events, can then cause the focus to shift even closer to individuals and the ways in which they interact with the world (Freire, 2004). More importantly, this space can continue to enable individuals to center their ways of knowing and being within their own familiar contexts (Heath, 1990; Moll, 2000).

\section{Purpose of the Study}

The purpose of the overall study was to evoke, listen to, and learn from the stories of women who had "risen from the ashes" of their experiences with marginalization and abuse in order to understand how their storying mediated their experiences with being silenced, resisting/talking back, and developing resilience. It was also intended to foster awareness and appreciation of the entire spectrum of women's experiences.

\section{Literature Review}

\section{Women's Ways of Knowing (WWK)}

WWK addresses different types of knowledge that women have: received, objective, procedural, constructed, and the knowledge of silence. The knowledge of silence, which is the last knowledge addressed in WWK relates to women's feelings of inadequacy, disconnection, and voicelessness. Although it is the last perspective addressed by WWK, it is presented as women's first stage of knowing and is experienced by many women, especially those who have been situated in contexts and/or lives of instability, chaos, abuse, or isolation. Some women transition from this way of knowing to deeper, more articulate ways of knowing as they begin to understand the truth that lies within selfknowledge, while others never progress beyond the knowledge of silence for their entire lives. A large part of knowing silence is also feeling powerless, so women who have only this way of knowing feel capable only of taking in others' knowledge. For these women, others who are in authority are the holders and keepers of all truth, while they are the receivers of whatever truth those in power provide. 
Women who have knowledge only of silence also reside in the fixed positions of knowing their stationary positions and in not being heard in those positions (Belenky et al., 1986).

\section{Critique of Women's Ways of Knowing}

WWK has been criticized as a one-size-fits-all construction and one which treats women's experiences collectively rather than taking into consideration their diverse backgrounds and lived experiences and the different intersections in their lives (Collins, 1991 Lather, 1992). It has also been criticized for its inability to demonstrate knowledge that is unique to women or to their experiences (Longino, 1994). Another major critique has been WWK's ideological notion of silence being an immobile space, in which women cannot speak. It has discounted the learning that can be gained while an individual is in the position of being silent. First, as Collins (1991) and Lorde (1977) argue, individuals are never completely silent. Second, as Collins (1991) argues, silence can be an empowering space in which to "transcend the confines of race, class, and gender oppression" (p. 93).

What is problematic is the failure of such perspectives as Women's Ways of Knowing, in their attempts to delineate stages in women's resistance to patriarchal values and behaviors, to generalize women's experiences with and responses to oppression without considering the various individual ways in which gender identity intersects with other social identities. Intersectionality, as noted by Shields (2008), as a comprehensive perspective with a "particular emphasis on the integration of studies of race, class, and gender" as well as other axes such as age, ability, and sexual orientation (pp. 99-100), has become an influential perspective from which to acknowledge and understand women as diverse individuals who have diverse experiences, and has provided a space for inclusion (Carbado, et al, 2013; Fernandes, 2010; Patil, 2013; Shields, 2008).

\section{Literacy}

Literacy is the use of speaking, writing, and other cultural practices to create meaning (Barton, 2001; Heath, 1983; Kern, 2000). Literacy is not merely a skill, but a dynamic process that moves across various communities, discourses, and cultures. As Pahl and Rowsell (2010) state, literacy "involves many different scripts, and it can exist in many different languages and settings" (p. 3). For the sake of this article and its implications for reflective digital narrative practices, I conceptualize literacy as artifactual (Pahl \& Rowsell, 2010).

From a widely held perspective, which was also adopted in the study addressed in this article, literacy is construed as a sociocultural practice in which the individual is able to interact with others in social spaces amenable to sharing experiences and enacting a wide range of literacy practices, including family and out-of-school literacies (Bakhtin, 1981; Garcia \& Gaddes, 2012; Heath, 1983; Vygotsky, 1997). Individuals' reading, writing, and other expressive practices convey the significance of values, relationships, and objects in their lives. Literacy is also defined as culturally embedded practices and behaviors or discourses (Barton \& Hamilton, 2000; Gee, 1998) that create meaning in their lives.

As a diverse sociocultural practice (Barton \& Hamilton, 2000; Cazden, et al, 1996; Gonzalez et al., 2005) that also involves the use of multiple discourses (ways of talking, behaving, and interacting) to navigate different contexts in daily life (Barton \& Hamilton, 2000; Gee, 1998; Jones, 2006; Kern, 2000), literacy is also a network of cultural practices that comprises much more than reading and writing. Literacy, which involves individuals' diverse practices and modes of expression, enables them to draw richly on their "Funds of Knowledge" (Gonzales et al., 2005; Heath, 1983; Moll, 2000), which are understandings and knowledge that they have for navigating their home and community spaces and for making meaning in their lives, which have often been storied as resources (Gonzalez et al., 2005). 


\section{Marginalized Ways of Knowing}

As Belenky et al. (1986) observe, intuitive ways of knowing have long been marginalized by the predominance of scientific methods as the source of valid knowledge:

Relatively little attention has been given to modes of learning, knowing, and valuing that may be specific to, or at least common among, women. It is likely that the commonly accepted stereotype of women's thinking as emotional, intuitive, and personalized has contributed to the devaluation of women's minds and contributions, particularly in Western, technologically oriented cultures, which value rationalism and objectivity. (p. 6)

Dillard (2012) argues for knowledge and inquiry that honor individuals' experiences by privileging their rich and diverse remembering, stating:

We have been seduced to believe that scholarship that is 'good' (i.e., legitimate and worthy of consideration) has no relation to the body and spirit, is strictly of the mind, and then only of those minds that are not Black, female, or concerned with spirit. (pp. 19-20)

Goldberger et al. (1996) critique mind-body dualism, which conceives of individuals' minds and bodies as separate entities, arguing:

mind-body dualism, tracked across time and the evolution of Western thought, has resulted in the pitting of reason against emotion and male against female. Such a split has contributed to the persistent dichotomizing and stereotyping of modes of thought and ways of knowing and being. (p. 14)

Embodied knowing (Goldberger et al., 1996; Pitts, 2003), which opposes the idea of mind and body as separate, can facilitate ways to communicate complex meanings gained from knowledge of crucial experiences with abuse and oppression (Pitts, 2003; Talvi, 2000). As posited by Pitts (2003), embodied ways of knowing, which may by expressed in such ways as body modification, may allow women to subversively reclaim their female bodies: "Women's subcultural body art violates beauty norms in a number of ways, and according to the rhetoric of body modification communities, subverts the social control and victimization of the female body" (p. 49). Connected knowing, referring to knowing oneself as a means of knowing others (Anzaldua, 1990), which is often overlooked and ignored (Belenky et al., 1986; Dillard, 2012), is a way of knowing that is highly related to storying one's life. The research findings discussed in this article relate to the participants' ways of knowing their selves and bodies and through these knowings, their mediated experiences of understanding others around them.

\section{Conceptual Framework}

Storying allows others to bear witness, as Lather and Smithies (1997) suggest, which entails the obligation "to look with restraint as we bear responsibility to the women who have told us their stories" (p. xvi). This sharing can bring healing (Kidd, 1996) and, further, represents women as individuals who have dynamic ways of voicing their experiences. As Luke (1994) posits, "Women have different ways of speaking and a different relation to language and knowledge" (p. 213). As such, Women's Ways of Knowing Silence (Belenky et al., 1986) and women's talking back (Collins, 1991; hooks, 1990) were the two chords of theory that were foundational to this research study. Artifactual Literacies (Pahl \& Rowsell, 2010) was also an important piece, as it provided richness related to the three participants' stories as artifacts themselves, as well as providing connectedness to the bodily and embedded artifacts that were parts of the women's lives. 


\section{Methods}

\section{Narrative Inquiry Design}

Freire (2004) reminds us that individuals exist "historically, culturally, and socially" (p. 97) and that these dimensions of their lives are shared with others through dialogue as innate human process and an "existential necessity" (p. 88). Using Daiute's (2014) narrative inquiry perspective as an inquiry design to study women's storying of their experiences allowed for understanding women's narratives as "accounts of daily life, stories that spring from the imagination, vignettes of daily life" (p. 2). Narrative inquiry, which is the practice of gleaning stories as data and then analyzing them for significant emerging themes (Daiute, 2014), allowed for "small stories" (Pahl \& Rowsell, 2010, p. 40) or meanings to emerge.

\section{Research Questions}

The research question and subquestions evolved as the study began to center on the narrated lives of three women from diverse backgrounds who lived in the Southwestern and Midwestern regions of the United States. The central question which guided the study was How do women from diverse backgrounds use storying as a space to make sense of their crucial experiences? Other questions that helped in understanding the women's stories and why these were told focused on how the stories mediate the women's crucial experiences, and how the stories become paradigms of the women's individual experiences.

\section{Narrative Analysis}

According to Daiute (2014), narrative analysis enables the telling of individuals' stories, and at a deeper level it seeks to understand why stories are told as they are told. Narrative analysis was helpful in locating the more elusive data of expressive language and participants' values as they were embedded in the primary data. Narrative analysis also allowed for paying close attention to the stories themselves as they emerged as embodied ways of speaking about personal and systemic injustices (Miller \& King, 2011).

Values analysis helped to identify participants' reasons for telling the smaller and larger stories of their lives (Daiute, 2014). Pahl and Rowsell (2010) describe values analysis as "a way to identify narrative meaning in terms of values expressed in and interacting with narratives" (p. 68).

\section{Intersectional Analysis}

Mackay (2013) states that intersectionality “usually refers to the study of how power works (or doesn't work), and how various oppressions intersect; it means focusing on power relationships" (p. 1). As a theory rooted in black feminism and critical race theory and originally proposed to dismantle historical marginalization occurring in fields such as law (Carbado et al., 2013), intersectionality can also be used as a tool of analysis for deconstructing the underlying structures of power that influence and impact individuals' actions and behaviors (Mackay, 2013).

For the research study that is discussed in this article, intersectional analysis allowed for ways to approach and understand unexplored place of three different kinds of women's storying rooted in their diverse lives. 


\section{Coding}

First, significant episodes within each participant's crucial event that emerged from her storying through journaling, letter-writing, oral storying, and/or making a collage were coded. Within each episode, initial coding (Charmaz, 2014) was used to identify significant action, identity, and meaning. Initial codes involved using in vivo (Saldana, 2016) featuring the participant's own language, to form future categories. After the initial coding, transcript data were reread for highlighting participants' values and reasons for telling their stories (Daiute, 2014).

While conducting initial and focused coding, ways of knowing emerged and were then color coded. Intersectional analysis was then used to code for point of view located in the women's different intersections of gender, socioeconomic status, religion, and family status, which, along with the women's personal communication styles, indicated their positionality with regard to the experiences they had shared.

Each story the women shared was used to uncover the deeper meanings of what they were storying (Clarke, 2005; Daiute, 2014), and as the stories unfolded, meanings emerged. Each story was viewed as a whole, including the context within which it occurred and the motivation of the person telling the story. The context of each of the women's interviews, along with the researcher's own emic knowledge of some of the stories' backgrounds were considered.

Narratives emerged from first cycle in vivo initial and narrative coding, and from the second cycle focused coding. Narrative coding was further used to pay close attention to each participant's purposes for storying their experiences. Settings were also important because oftentimes these were often the locations of trauma and silencing. Plot was coded in terms of the significant actions of the participants and others in the participants' stories, always reflecting the former's point of view. Capturing spoken features was important to make the voices of the participants present in the report.

Besides bearing in mind participants' values, focused coding (Charmaz, 2014) was also used to consider the women's belief systems.

\section{Participants}

Participants in the study were three women from diverse backgrounds. Each of the participants was invited to the study because of her willingness to talk openly about her experiences, particularly about crucial or highly significant events that had impacted her life. Each woman was then interviewed using a three-cycle interview process (Charmaz, 2014; Seidman, 2013) with a beginning, intermediate, and ending interview for each crucial event, with additional interviews to clarify the data. Interviews (3045 minutes in length) were conducted using this cycle to understand participants' lived experiences and the meanings within them and to richly contextualize the knowledge that was received. Initially, the participant was asked to tell, from beginning to end, about the selected event (one that we had agreed upon) and the people involved in them. The second interview involved talking about episodes of the event. During the third interview, the participant elaborated upon each of the selected events by talking about the meaning that she drew from it.

In addition to the interviews and the storying they entailed, data were collected from multiple sources representing various literacy practices, which included letter-writing, journaling, collagemaking, as well as participant observations. Each of the data sources contributed uniquely to the key themes that emerged as the research question How do women from diverse backgrounds use storying as a space to make sense of their crucial experiences? was pursued. See Figure 1 below for the data graphic representation. 


\section{Chowsie}

At the time of the research study, Chowsie (pseudonym) was 88 years old and lived in a small town in the Southwestern region of the United States.

Chowsie's worn and aged hands, bodily artifacts that testified to her life story, spoke eloquently of her accomplished independence and survival despite being impoverished. Our interviews and her sharing of her journals and letters allowed me some insight into the intersections of her life as a Caucasian woman, a former teacher, an inhabitant of Taco Town (a primarily Latino section of her town) and an individual whose self-reliant labors have been performed through her own body. Being silenced, resisting/talking back, and maintaining resilience were the dominant categories of Chowsie's stories. Her narrative was essentially the tale of a strong woman's will to survive and to thrive despite difficult circumstances. Each of the smaller stories I drew from within it made sense of a different facet of her life. To fully capture her voice, I titled these stories with her words: "The Rape," "Punishments," "School Teacher," "Building the 'Ole Shed,"” and "The Quirt." Chowsie's storying as an interactive process provided a dynamic space in which she spoke freely and I listened, sometimes offering my own experiences to testify. I then restoried her experiences. Chowsie also narrated her experiences through journal writing and letters she wrote to me. Chowsie not only performed literacy practices such as journal and letter writing for the overall research study but had also used literacy practices such as letter-writing through the years. All of these facets of literacy as a practice of sharing and listening that emerged in the form of Chowsie's journals and letters were channels through which her stories streamed and through which the reader will be able to appreciate her in my restorying of her experiences.

\section{K}

At the time of the research study, $K$ (pseudonym) was 35 years old and lived in an urban area in the Midwestern region of the United States.

K's interview data and journals helped me understand the intersections of her life as an African American woman, a spouse, and a full-time mother, and her tattoo served as a visual text to frame her narrative and my analysis. Being silenced, resisting/talking back, and maintaining resilience are the dominant categories within the larger narrative of K's pregnancy, her son's death, her inscribing a permanent memory of him on her body with a tattoo, and her subsequent achievement of a life goal. The salient events of her pregnancy, her son's death, and her tattoo seamlessly developed as I reflected on her emotive ways of speaking and writing. With her collaboration, I titled the stories representing these episodes to fully capture her voice: "The Difficult Pregnancy," "A's Death," and "Forever My Angel: Carrying My Son, Carrying My Story." In the next section, I relate her story holistically, followed by my analysis of its dominant themes. K's storying as an interactive process provided a dynamic space in which $\mathrm{K}$ spoke freely and I listened, sometimes offering my own experiences to testify. Centrally, K storied through her tattoo, which was an embodied literacy practice because of its symbolism that related to her backstory of trauma and silencing. Storying her tattoo was also an embedded literacy practice because she had storied it to many others in her daily life. $\mathrm{K}$ was able to story her experiences by enacting different literacies, which included collage-making that I requested at the onset of this study. Her collage contained language and symbols related to her last pregnancy, as well as a letter she had written to her deceased son. All these facets of literacy, sharing and listening, and K's collage-making were channels through which K's stories flowed and are brought together in my re-storying of her experiences. 


\section{Rhonda}

At the time of the research study, Rhonda (pseudonym) was 50 years old and lived in an urban area in the Midwestern region of the United States.

Rhonda's interviews were like vessels in which she offered her experiences and stories so I could understand and appreciate the intersections of her life as a Caucasian woman, a pastoral spouse, mother, and Cradle Roll teacher, in the center of which was a silence created by a grief she found she could not meaningfully share. This grief was the loss of a child during a failed pregnancy, signified by the photograph of Rhonda's hands holding a white rose. Being silenced, resisting/talking back, and maintaining resilience are the dominant categories of the narrative of Rhonda's miscarriage, its aftermath, and her subsequent embodiment (Nieves, 2012) of hope in her teaching, which unfolded in our interviews as I reflected on her emotive way of speaking. I titled the stories representing these episodes to fully capture her voice: "Loss of My Angel," "New Pregnancy: 'It Was Hard to Let Go,"” and "Joy in Teaching."

Rhonda's storying as an interactive process provided a dynamic space in which she spoke freely and I listened, sometimes offering my own experiences as a way to reciprocate. Though she shared most of her storying orally, as she did not feel comfortable writing, she also created a collage which further demonstrated the resilience that emerged in our conversations. The literacy practice of letter-writing, which she had enacted soon after her pregnancy loss, also emerged in her data. All these facets of literacy, sharing, and listening, and Rhonda's reflections on her interactions with others as well as her letter-writing, were channels through which her stories flowed to be shared in my restorying of her experiences.

Figure. 1. Types and number of data for Chowsie, K, and Rhonda

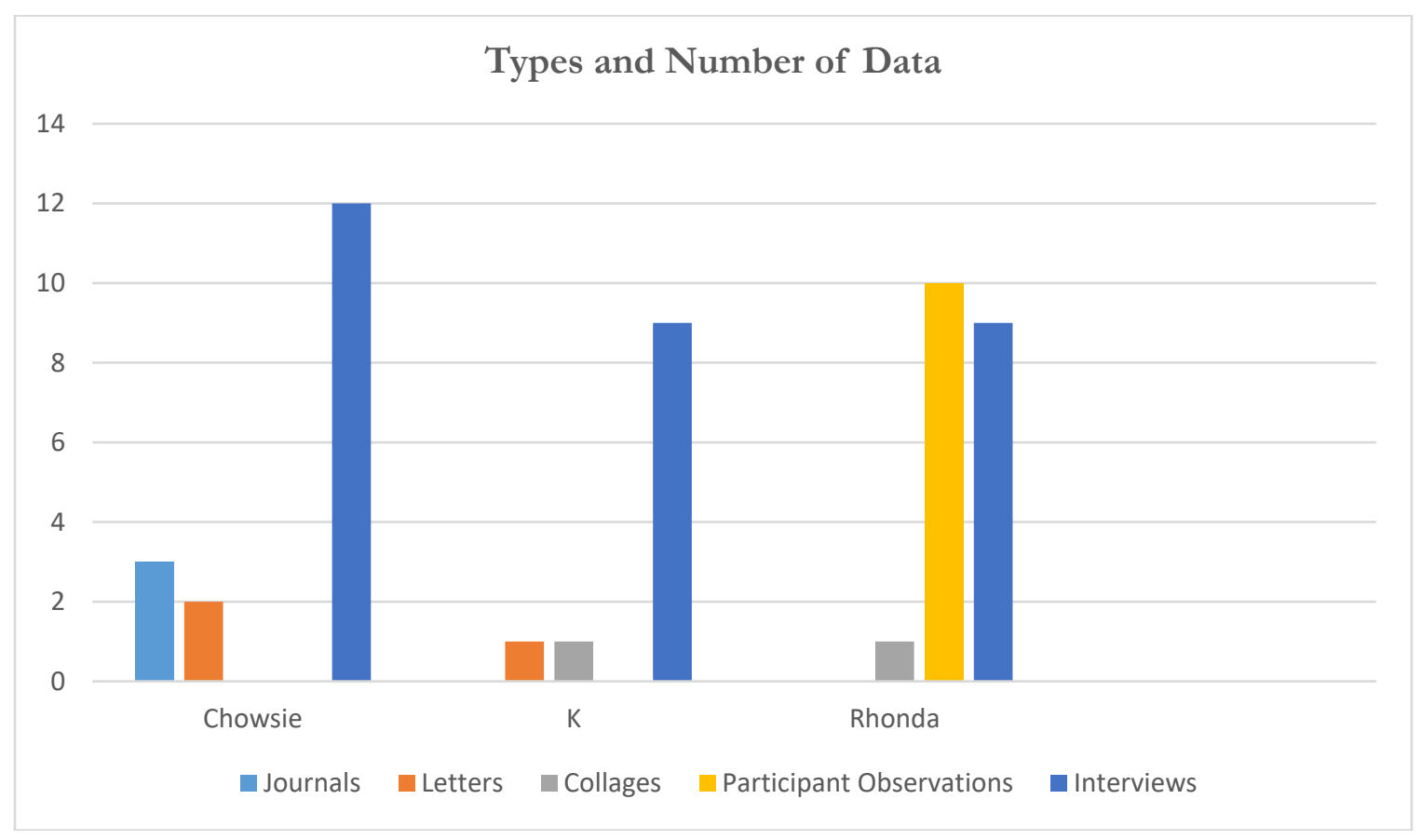




\section{Terms}

Before addressing the women's stories and analysis, I offer some introductory terms and how they have been defined for discussion about the overall research study. Other terms will be addressed in the following sections. Silence is a term that I use to signify a space in which an individual is kept from speaking and being heard but which also may be used as a temporary haven for repositioning oneself in relation to others. Agency is a term I use to describe an individual's willpower and action taken to produce a particular result. Intersectionality is a term I adopted from Third Wave feminism to refer to the intersections among different social identities such as race, class, gender, and religion. Women's expression is a term I use to counter the version of silence as a fixed state that Women's Ways of Knowing presents and to describe women's diverse ways of "talking back" to others who seek to oppress them.

\section{A Narrative Analysis of Silencing, Resistance/Talking Back, and Resilience Silencing}

Silencing that prevents a woman from speaking up and sharing her experiences with others is a way of suppressing her "authentic voice" (Houston \& Kramarae, 1991, p. 389). I define silencing as a practice that others enact to ignore or deny a person's perceptions and perspectives. In Chowsie's storying, two distinct kinds of silencing emerged. Physical silencing was imposed by others who literally forced Chowsie down through acts of violence against her body. The physical abuse she experienced from her parents and rapist when she was very young caused her to fear further repercussions should she tell others about the corporal punishments and rape she endured, and this fear caused a silencing of her story, a period when she did not story her experiences to others. Unlike the speaker in "The Yellow Wallpaper," whose end was self-destruction, Chowsie successfully leveraged agency from her story silencing by intentionally enacting behaviors and ways of talking back to those who had sought to control her voice. Her other stories, which included her experiences of teaching and building her shed, were ones she was able to share with others through the years. Thus, the story silencing related only to Chowsie's experiences of abuse at a time of vulnerability in her life. Specific examples of this physical muting and story silencing are discussed in the following sections.

\section{Physical Silencing as a Catalyst for Story Silencing}

These stories, which magnified the tensions of silencing, were locations of meaning construction (Alcoff, 1988). "The Rape" was such a story, which magnified the physical silencing Chowsie had experienced at the hands of one in whom she had placed trust: "He climbed in on the side. He pushed me over backwards and raped me. I hollered and he put his big ol', rough hand on my mouth and took me out to sea. He made me bleed. He broke my hymen." Rape is the epitome of patriarchal violence, with a more powerful individual exercising brutal physical control over a less powerful individual (hooks, 2015). As Chowsie testified in stark language, the rapist physically compelled Chowsie's silence during his forceful enactment of violence by overpowering her and invading her body. In the language she uses, Chowsie restories this act of violence which she suffered, but she does so not simply for the purpose of telling the story of a girl who lived through a traumatic experience. Her language is purposefully frank and therefore forceful, just as her rape was forceful. In her storying, both in her interview and in her journal writing, Chowsie spoke harshly, as if she were reliving the rough hand, the internal breakage, and the bleeding, in both oral and written language that can be considered a "language event" (Pahl \& Rowsell, 2010, p. 40; Barton \& Hamilton, 2000) in that Chowsie had used raw language to convey the deeper meaning of having one's body violently assaulted. 


\section{Hearing without Listening}

In the episode "The Hard Pregnancy," which was the background story for K's tattoo, K described her husband's continued opposition to her decision after she became pregnant: "I was six weeks along. And I thought, he's my husband and he'll eventually fall in line with my plan. Um, but, no he didn't. He verbally abused me the entire time." K's husband held to his own perspective that their family was not financially stable to be able to have a third child and ignored K's perspective. In prevailing over his perspective, she evoked his retaliation in the form of verbal abuse, which, as hooks (2015) notes, can be a form of patriarchal violence. K's husband's response was an enactment of an ethic of domination, in this case over her emotions because he could not control her body. It was also an "unforced silence" (Kirkland, 2013, p. 35), an act of ignoring K's perspective. While he maintained his perspective, $\mathrm{K}$ also held to her own perspective of having the right to become pregnant despite their financial circumstance because it was her body that was involved, as a result of which her body became the site of contention. In following through with her decision, she faced continued opposition from her husband: "And during the pregnancy, um, I was told, um, you know, I was going to gain weight, and [my husband said] I'm not attracted to you. And it caused me to look down on myself, you know" (K, interview). The above passage shows K's experience of her husband's disparaging remarks as an attack on her identity and her meaning-making of the experience (Alcoff, 1988; Evans, 2003), in which she reflected on her husband's behavior and words as damaging. K's meaning-making also led her to act in ways that were reactionary to her husband's accusations so as to prove him wrong: "Everything that I could do, because you know, I wanted to prove to myself and him that, you know, I'm not going to gain a whole bunch of weight, you know, during this pregnancy I'm going to stay active, blah blah blah." K's storying of this issue of body image during her pregnancy speaks of a culturally constructed narrative of the need for weight management because of seeing "flesh as a problem" (hooks, 2015, p. 35), to which K subscribed uncritically, indicating her deference to his and

to the socially condoned perspective while self-silencing any alternative perspective she might have held regarding her body during pregnancy.

\section{Story Silencing}

Rhonda's internalization of others' silencing, which resulted from their resistance or inability to acknowledge her storying as she intended it and sympathize, denied her the opportunity to talk about her experience with others. Rhonda reflected on times she attempted talking with her mother:

What made it really hard for me was when like, even when my mom was supportive and stuff, um ... she did tell me, she said, "You know, I don't really know what to say to you because I never lost a baby."

Like her mother, others in her family seemed incapable of empathizing because they had not experienced a miscarriage: "You know, my mom had never lost a baby. My mother-in-law had never lost a baby. My sister-in-law had never lost a baby." Even more than their inability to put themselves in Rhonda's situation, the language in their responses showed a lack of active listening (Uttal, 1990) and sincere questioning that would demonstrate some effort to try to understand and value her experience even though it was outside their own. Rhonda recalled another instance when she felt silenced, this time by her hair stylist's apparent fear of sharing her experience:

And I was surprised because like I had gone in to get my hair done like a week afterwards and it was actually one of the first things that the girl who had been doing my hair - she noticed that I wasn't wearing a maternity top because that was like the first thing I did as soon as I got the pregnancy test. And so she was almost afraid to even talk to me about what was going on. It was like she just knew 
something was wrong. It was really weird because I had that response from her. She was like really afraid to share anything with me.

As previously shown in K's story, others sometimes have difficulty listening and responding to one's difficult experiences, as was the case when Rhonda's stylist was afraid to open conversation about Rhonda's loss. As noted earlier, following the results of her pregnancy test, Rhonda had come to the salon to have her hair styled by the same woman, with whom she enthusiastically shared her news, but after her miscarriage, she felt as though she should not to talk to others about her loss. This selfcensoring speaks to women's common practices of keeping their conversations acceptable on the surface, not allowing painful personal experiences to emerge (Uttal, 1990). As an "identifying event" (Hardy \& Kukla, 2015, p. 107), Rhonda's miscarriage was an incident that was perplexing because it was difficult to make sense of the loss and so caused her to question herself. Also, Rhonda's empowering narrative of a woman who was so happily pregnant that she had openly shared the event with others had transitioned into an empty narrative of a woman whose pregnancy had failed and had nothing to show from the loss except no longer wearing maternity clothes. This noticeable difference, which signified an unhappy event, made others hesitant to approach the subject, which resulted in a story silencing. Different situations and individuals in Rhonda's life hindered her storying in different ways. Rhonda reflected on how family members silenced her by being silent themselves:

- "He [Rhonda's husband] doesn't talk about it too much, because I don't think he wants to stir up any emotions and then deal with that."

- "And my mom, of course, I know she knows that I'm hurt about it, but I mean, she doesn't bring it up or talk about it."

Though Rhonda's husband and mother did not act in ways that prevented her from speaking, their avoidance behaviors discouraged her from talking naturally from her own perspective of having suffered trauma and loss and thus suppressed her "authentic voice" (Houston \& Kramarae, 1991, p. 389).

\section{Resistance/Talking Back}

\section{Resistance through Embodying the Artifact of Trauma}

Women often resist by talking back as a way of responding to dehumanizing actions against themselves, their identities, and their stories. Despite Chowsie's facing silencing as a victim of physical violence, she was able to story her resistance/talking back in behavior which was powerfully symbolic. One of the most potent examples of this resistance/talking back was her enactment of a routine of normalcy while projecting the trauma she had experienced through her clothing: "And I wore the little dress the next day and I hemmed it and sewed it and those were the days when you wore a dress to school." By mending and wearing the very dress in which she had been raped, Chowsie symbolically enacted self-repair while publicly displaying an artifact of the trauma, which negated the silencing (Uttal, 1990) and talked back to those who would judge her, even though they were not aware of either the rape or her resistance to its effects. Chowsie's wearing of the dress outwardly demonstrated adherence to the cultural norm of the time, "those were the days when you wore a dress to school" (Chowsie) but more deeply represented resistance to the cultural norm that marginalized women's perspectives (Tong, 2014).

\section{Resistance through Embodying the Tattoo}

Women tend to place tattoos where they can easily be concealed (Fisher, 2002; Horne et al., 2007). K resisted this practice by conspicuously displaying her tattoo on her left upper arm. When I asked how 
others reacted to the tattoo, she stated, "Tattoos are conversation starters, they can tell a lot about a person." The tattoo mediated her story by allowing $\mathrm{K}$ to talk about painful experiences that others were likely to find difficult to hear: "When most people ask about a tattoo, they aren't expecting to hear a sad story." She described how this story had created discomfort in conversations: "When I tell people about my tattoo, they get embarrassed. Embarrassed that they have somehow caused me more pain by making me explain or relive what happened." However, speaking openly about her life and the part of it represented by her tattoo provided a way for her to externalize the trauma she experienced (Leader, 2015). Also, having an elaborate tattoo on prominent display was a way for her to talk back to those in her life who have sought to deny her self-image and control what she did with her body. Stengle (2003) has argued that women may acquire tattoos to "regain control over their bodies" (p. 22).

K's tattoo may thus be interpreted as her way of visually storying a life that, in Symington's (2004) words, comprises "multiple, layered identities derived from social relations, history and the operation of structures of power" (p. 2).

\section{Resistance through Jaded Language}

During one interview in which she described the language she tended to use when she reflected on her experiences, Rhonda used the word jaded, which suggests an element of cynicism in her responses to others' dismissal of her agency and a degree of self-irony in looking back on her behaviors. In the Urban Dictionary (2017), "jaded" is defined as having a feeling of overwhelming emotional numbness after having experienced negativity. Just as Rhonda's enacted behaviors in the hospital were ways of resisting others' silencing, the very language she used to story those behaviors showed what she viewed as her jaded resistance in talking back both to the medical staff members and to others in her life who had privileged their own perspectives and ignored hers. Rhonda's jaded language was a language of power (Fairclough, 2001) because it mediated the emotional numbness she felt to describe pacifying practices that were enacted by others. Though I might have found other words to appropriately describe Rhonda's resistance, I also use the word "jaded" in this writing to honor her authentic voice. Rhonda's jaded words (bolded below) unapologetically described her experience of medical care while in the hospital:

- “'I want to make sure that you're in P.O. [having no more medication to take] after midnight,' and all that good junk"

- "That to me was a crock"

- "He patronized me with the tests and all that"

- "But at least the doctor did pacify me"

- "Maybe it's because they just knew I was so much of a basket case, they just wanted to knock me out and get started"

Through her storying and derisive language, Rhonda was able to convey the frustration she had felt with efforts to calm her into compliance (Kirkland, 2013). Expressions such as "patronized me" and "pacify me" are jaded phrases of talking back that identify Rhonda's self-knowledge of having been in a powerless position as a patient who had little authority over her medical care. These, along with others, "all that good junk" and "knock me out" are jaded as well and reveal her own perspective on the medical team's effort to hurry her through the process of acknowledging her miscarriage and undergoing the D\&C. 


\section{Resilience}

\section{Chowsie's Resilience}

Chowsie's storying revealed not only her resistance to physical and story silencing, but also her meaningful resilience and the values she gleaned from her experiences. The story of "The Quirt" revealed the meaning she had made and the strength she drew from her father's physical punishments. Chowsie told the story of her father's cool wrath when she inadvertently contaminated a bucket of milk, as he calmly finished the chore he was doing, then beat her mercilessly with a leather strap, and finally ordered her to complete her work. This story was told not in self-pity or complaint but as an element in her development into the person she had become: "This kind of raising got me set for life. I've always accepted and faced any issue that may and did occur in life. Didn't fear anything as a wilting violet would say. I did my best to do it." Chowsie's meaning making from her experiences with enduring her father's physical punishments related to her capacity for hard work. In the interviews, Chowsie admitted that her life on the farm, where she had been perceived more as a farm hand than as a child, had been difficult, but she had gleaned from it the value of being able to work hard and help her family. This robust value, which was the opposite of the fear of a "wilting violet," became a mantra that carried her through "any issue that may and did occur" in her life and was still strong in her storying of the work she accomplished on her property.

\section{K's Resilience}

Regarding K's purposes for her tattoo, permanence and nonpermanence emerged as subthemes of resilience. In 2015, eight years after A had passed away, I asked K to create a collage. As part of the collage, she wrote a letter to A in the present tense, addressing him as he was before his death. The letter also alludes to a future in which she will not forget him:

Which because that ... You know I am an atheist, and I don't just believe like how I was raised that I will see him again, so that is my memory of, of him. Is, is that ... you know, that he was here. So that's basically the reason for the tattoo. Kind of how, kind of sort of, um, to kind of keep that memory with me so I never forget, you know, you know, forget him.

Carrying her son on her body as a visual representation of her experiences was a way for $\mathrm{K}$ to keep his existence permanent as an absent presence (Maddrell, 2013). Her belief, as she stated, was that she would not see her son again, so the tattoo enabled her to stay connected to his memory: "I get to look at them [K's living sons] every day, but I don't get to look at him [A] every day, so the tattoo is the kind of ... is the memory of him." As Stengle (2003) posits, wearing a tattoo can be a memorializing practice to connect spiritually with someone who has passed away. K noted, "I wanted to do something kind of permanent to keep his memory alive." The visual storying of her tattoo, a marker/commemorator of a life event (Fisher, 2002; Wohlrab et al., 2007) helped K to commemorate A's life, connect with A, and transition through the crucial event of his death. Her storying was a way to heal; as she stated: "Telling people about my tattoo is actually therapy for me in a way."

Sharing her story with others was also a way for $\mathrm{K}$ to help others. As a mediator of her storying, her tattoo became a way for her to nonverbally empathize with others' difficulties by testifying to her own troubling experiences. In "Forever My Angel: Carrying My Son, Carrying My Story," K reflected on what her tattoo and storying do: "There are young mothers out there that have three kids, two or three kids and she's young, in her 20s, early 20s and she's doing a lot, there's a lot on her shoulders. You can do it, you can get through it. Never give up," which was her own version of this mantra of resilience that she offered as a testament to her own experience of pushing through challenges. K's willingness to story her experiences for others allowed her to use her body as a social and political 
space (Pitts, 2003; Woods, 2012). By talking with others about her experiences when they asked about her tattoo, she could explore tensions related to sociocultural and patriarchal pressures, such as others' efforts to control her female body and to silence her story.

\section{Rhonda's Resilience}

Collins (1991) reminds us that "People are rarely powerless, no matter how stringent the restrictions on our lives" (p. 110). Though Rhonda's ability to story her pregnancy loss with family and friends was limited by their unwillingness to allow her to share her experiences authentically, she was able to share with others. She described one opportunity that allowed her to talk openly about her loss:

One night, I was really depressed, so, um ... and the only thing I could find was a suicide hotline. And I called them, and I said, "I'm not really suicidal, I'm just really upset." And it was a guy that answered the phone, which I was kind of like, "I don't know." Understanding this guy, he was actually very good, and when I was sharing my thoughts and stuff, his thing was, "It sounds like you have not really come to terms with the one pregnancy, and you really need to do that, because you've got this other pregnancy going on."

The man's listening and healing advice stimulated Rhonda's writing to her baby:

I don't remember now exactly how long it was, but it was, um ... on notebook paper, and it was several sheets. And I kind of just wrote to the baby about how much I had wanted to get, um, pregnant, how excited. It was a planned pregnancy. What I was planning on it being named. Plans for the future. I mean, I just kind of talked like it was here, and, um, how I was really, you know, sorry that things hadn't worked out. Um, and then I shared the thing that it was still my hope that we would get reunited.

This passage illustrates that writing to her baby was itself an act of resiliency, which might have been difficult to carry out immediately following her miscarriage, especially given others' lack of support. However, the opportunity to talk with someone who listened and gave positive feedback allowed her to come to terms with her loss and honor its significance, as expressed in such comments as "how much I had wanted to get pregnant" and "It was a planned pregnancy," which show the hope Rhonda had invested in that new life and which had survived as a hope for the future in which she and the child would be reunited. In the space and privacy of letter-writing, Rhonda was able to freely inscribe the meaning of her loss without others attempting to manipulate or quiet her perspective. She was also able to write about her belief, despite others' distinctly opposite views, that she would see her child someday.

\section{Findings}

This study was premised on the principle that women's storying can be an important literacy practice through understanding how women from diverse backgrounds use storying as a space to make sense of their crucial experiences. The findings that are discussed in the following sections relate to how each woman was able to use stories for mediating her crucial experiences with silencing and how the stories exemplified each of the women's individual experiences.

\section{Silencing}

Physical silencing emerged as others' actions of physically restraining a woman's movement and voice during acts of violence against her body, revealed in Chowsie's storying of her rape and parents' corporal punishments.

The silencing of hearing without listening occurred as others overrode the woman's attempt to express her experience by asserting their own opinions without regard for her perceptions or 
perspectives. To frame this kind of silencing, I use the narrator's perspective from Charlotte Perkins Gilman's 1892 story, "The Yellow Wallpaper," in which a woman suffers from depression and experiences silencing and eventually psychological disintegration because of her husband's ignoring of her emotional needs. The contrast between the narrator of "The Yellow Wallpaper" and my participants' own experiences is that the women in my study were resilient and overcame others' control rather than succumbing to their situations. Hearing without listening occurred in K's and Rhonda's cases, in which each woman's perspective on her pregnancy fell on the deaf ears of relatives and others, who listened only to themselves. K's storying revealed hearing without listening when her husband and other family members privileged their own perspectives related to K's belief system and pregnancy.

Chowsie's storying did not reveal an episode of others' hearing without listening, as her fear of consequences prevented her from even attempting to tell others about her rape and punishments, resulting in a period of silence.

The different kinds of silencing that the women experienced, however, eventually impelled resistance, and they converted the silencing into agency as they found ways to talk back in diversely subversive ways, which will be discussed in the next section.

\section{Resistance/Talking Back}

By "talking back" (hooks, 1990, pp. 207-211) and through choosing to speak about their lives, women powerfully resist oppression (hooks; 1990; Stewart, 1994). The women participants in the study were able to talk back through their implicit and explicit literacy practices. One way was through language. Each of the women in this study used unapologetic language as a way of talking back to the silencing she had faced.

The women's use of uncensored language that authentically communicated their difficult life experiences (Lather \& Smithies, 1997) was a resistance to the silencing they had experienced silencing that sought to discount their independence and capabilities as women. Along with their use of language, the women's behaviors were often acts of resistance and demonstrated how each leveraged agency from the silencing and embodied their experiences.

Memorialization (Hardy \& Kukla, 2015; Otte, 2007) emerged across all three cases as an act of talking back. Rhonda's actions of first writing to her deceased child and then collecting her hospital items (the hospital band and other items) and enclosing them in a checkbook box were acts of recognizing and naming her experience (Hardy \& Kukla, 2015; Pahl \& Rowsell, 2010) of the life that had existed within her at one time. The other women's memorializing also emerged as ways of talking back. K's embodiment (Nieves, 2012) of her son's existence in a tattoo and her letter-writing to him were ways in which she memorialized her experiences and talked back, revealing her harsh backstory. Chowsie's wearing of her defiled dress the day after her rape and letter-writing to the rapist memorialized her traumatic experience and were acts of unabashedly talking back not only to the rapist, but to a culture that often ignored women's voices and minimalized acts of violence against them.

The women's behaviors that emerged from their storying revealed the different values (Bye, 2005; McGill, 2011; Thiel-Stern et al., 2011) that each claimed, and these were connected to their manner of resistance. Chowsie's values of women being as capable of doing valuable work as men and of having the personal resources for "making do" were demonstrated in her storying and symbolized in her actions of independently building structures on her property with materials she scavenged or had on hand. These values were the mantras of her daily life, as demonstrated when she continued to 
use the phrase "making do" in our private conversations after the interviews. K's value of husbands treating their wives respectfully was a strong thread woven throughout her storying of becoming pregnant and her experiences during the pregnancy. Rhonda's values of life beginning at conception and the importance of nurturing children's knowledge and capabilities emerged throughout her storying of her pregnancy loss, the aftermath of the loss, and her teaching.

Each woman's storying narrated her intentional resistance to the silencing that is grounded in social and economic marginalization and testified to the profoundly vital nature of her lived experiences. K's strategic way of talking back as an African American woman who had survived the emotional traumas of a stressful pregnancy and the death of her child enabled her to resist silencing by talking in ways that would compel others to listen (hooks, 1990; Goldberger, 1996). Chowsie's talking back in both stories and accomplishments were also her strategic voicing of herself as a Caucasian woman with an underprivileged background, who had survived multiple traumas and always proudly provided for herself. As a Caucasian woman who had been silenced by the expectations of her role as a clergyman's wife, Rhonda talked back to voice the significance of her miscarriage and the tragedy of her lost child in defiance of those wishing to reduce her experience to a medical event rather than a personal experience. From this research I conclude that women resist silencing through dynamic ways of "talking back" as hooks (1990) meant the phrase, as evidenced in how the study participants used storying as a space to make sense of their critical experiences.

\section{Resilience}

Galvan (2006) describes resilience as a "going beyondness" (p. 163), that is, going beyond survival to achieve joy. Gonzalez (2006) provides an explanation of resilience that resonates with my conceptualization, as she states that it is "the enduring will to survive, and the refusal to be defeated by life" (p. 12).

To become resilient, women first become vulnerable by disclosing what has been suppressed or hidden in their lives to share and receive experiences and perspectives with others (Anzaldua, 1990; Minh-ha, 1990). As Minh-ha (1990) posits, becoming resilient involves an individual's willingness to connect with others, which may entail the release of hatred and past grievances, and requires being active agents in their own lives (Anzaldua, 1990).

Just as women are agents in their own storying (Brown, 2013), they are also agents in their own resilience. For the purposes of this research study, I define resilience as the will to persevere and prevail in the face of obstacles and setbacks, and in the context of this study, specifically to a woman's determination to survive and succeed in relation to experiences and interactions she has had in her life that have allowed her to share her story. The following subthemes explicate how each woman expressed resilience in her storying.

\section{Story Sharing}

For Rhonda, resilience first emerged through when she shared her story of pregnancy loss with the telephone counselor. She had attempted to share her experiences with family members and others in her life, but to no avail as they manipulated the conversations. However, when she was able to finally speak about her loss with the counselor, she felt empowered to write a letter to her deceased child in which she affirmed the hope she had had for a future with that child. K's sharing also emerged after a time of being verbally silent. She felt compelled to honor her and her son's lives by inscribing his story visibly her body, where it served as a "conversation starter" that also invited others' emotional expressions as they responded to her backstory. As testaments to her endurance, Chowsie's storying was also concretely shared when she described wearing the defiled and mended dress as an artifact of 
surviving the recent assault on her body and when she displayed the structure (the "ole shed") she had built with her own hands on her own property.

\section{Hope}

As the women in my study storied their experiences, their indomitable will not only to survive but to rise up was apparent, and through their literacy practices I was able to understand each one's hopes for her future. K's hope emerged through the embodiment (Nieves, 2012) of her tragedy in her tattoo, which communicated to others, "I feel like I have a story to tell." Her reflection on how she storied her experience in her tattoo revealed the hope that she wanted to impart to other young women experiencing the responsibilities of motherhood: "There are young mothers out there that have three kids, two or three kids and she's young, in her 20s, early 20s and she's doing a lot, there's a lot on her shoulders. You can do it; you can get through it. Never give up."

K's hope was also illuminated by the theme of permanence that emerged from her letter to A, her deceased son, and in the permanence of her love for him symbolized by the indelible inscription upon her body, which is discussed in the next subsection.

Hope emerged as a theme in the latter portion of Rhonda's storying as she expressed her joy in being a Cradle Roll teacher. The triangulation of her interviews and my participant observations with her collage depicted her faith in children's knowledge and capabilities juxtaposed with adults' discrediting of children's abilities, and how teaching children about God and a future in Heaven related to her hopes for seeing her deceased child again.

Chowsie's hope also emerged, as K's hope did, through sharing her story and knowledge with others such as her neighbors in Taco Town and with family members. Also, like Rhonda, her hope took the form of investment in the younger generation. Her nephew Calvin (pseudonym), whom she taught to build structures basic to daily living, had been an apprentice through the years. Toward the end of my data collecting, Chowsie told of a project in which, under her guidance, Calvin had successfully obtained materials through negotiation and had independently drawn up the plans and built a structure.

\section{Permanence and Impermanence}

Permanence and impermanence emerged differently in the women's storying. For K, permanence directly related to her tattoo, which was a permanent emblem of her son on her body. Impermanence directly related to K's belief that there would not be a future with her son. For Rhonda, permanence directly related to her hospital artifacts and the remembered letter she had written to her deceased child. The hospital artifacts were permanent reminders of her loss but also of her hope for seeing her child in the future. Impermanence also related to the temporality of the physical existence of her child and others' fleeting care for her loss. For Chowsie, permanence was enshrined in the "ole shed" as a permanent signifier of her survival and will to independently thrive.

From this research, it can be concluded that women's resilience is often chorded to and demonstrated through their sharing of their stories with others. Through their storying, the women's situatedness was apparent, but their resilience, which was shown to be socially and culturally constructed by their interactions and experiences with others, glowed. 


\section{Summarizing the Three Categories}

Because data was drawn from different media, including talk, writing, art, and recordings, different literacy aspects emerged across the data. Table 1 below shows these in relation to the participants' overall narratives, as well as the kinds of silencing each woman experienced, the evidence of their resistance/talking back in their stories, and the subthemes that demonstrated the resilience of each.

Table 1. Stories, Categories, and Literacy Aspects

\begin{tabular}{|c|c|c|c|c|}
\hline Participant & Narrative & Silencing & $\begin{array}{l}\text { Resisting/Talking Back } \\
\text { through Literacy } \\
\text { Practices }\end{array}$ & Resilience \\
\hline Chowsie & $\begin{array}{l}\text { Narrative of survival } \\
\text { from rape, corporal } \\
\text { punishments, } \\
\text { intimidation, and gender } \\
\text { and socioeconomic } \\
\text { marginalization }\end{array}$ & $\begin{array}{l}\text {-physical } \\
\text {-hearing without } \\
\text { listening } \\
\text {-story }\end{array}$ & $\begin{array}{l}\text {-wearing the artifact of } \\
\text { trauma } \\
\text {-journaling } \\
\text {-letter to the rapist } \\
\text { (remembered) } \\
\text {-letter to the researcher } \\
\text {-audial narration }\end{array}$ & $\begin{array}{l}\text {-Rising Up } \\
\text {-Teaching Others }\end{array}$ \\
\hline $\mathbf{K}$ & $\begin{array}{l}\text { Narrative of survival } \\
\text { from emotional abuse, } \\
\text { intimidation, and gender } \\
\text { and religious } \\
\text { marginalization }\end{array}$ & $\begin{array}{l}\text {-hearing without } \\
\text { listening } \\
\text {-story }\end{array}$ & $\begin{array}{l}\text {-embodying the tattoo } \\
\text {-letter to her baby } \\
\text {-collage } \\
\text {-audial narration }\end{array}$ & $\begin{array}{l}\text {-Rising Up } \\
\text {-College } \\
\text { Graduation }\end{array}$ \\
\hline Rhonda & $\begin{array}{l}\text { Narrative of survival } \\
\text { from pregnancy loss and } \\
\text { gender, religious, and } \\
\text { social status } \\
\text { marginalization }\end{array}$ & $\begin{array}{l}\text {-hearing without } \\
\text { listening } \\
\text {-story }\end{array}$ & $\begin{array}{l}\text {-letter to her baby } \\
\text { (remembered) } \\
\text {-collage } \\
\text {-audial narration }\end{array}$ & $\begin{array}{l}\text {-Rising Up } \\
\text {-Joy in Teaching } \\
\text {-Lactation Consultant }\end{array}$ \\
\hline
\end{tabular}

\section{Storying is a Literacy}

Storying in the form of narrating experiences orally, in writing, and in nonlinguistic modes is a literacy practice in that it is a construction of social meaning to be communicated and understood. In this process, smaller stories converge to become bigger stories (Pahl \& Rowsell, 2010). From the research, participants' smaller stories that emerged into larger stories were able to be succinctly understood. Through storying, participants reflected on their experiences and their literacy practices surfaced in the form of oral narration, journal and letter writing, collages, and self-styled body art. The specific stories, which captured the women's crucial experiences, became larger stories of experiences with silencing and of their refutation of it by finding ways of talking back to others through powerfully intentional behaviors.

\section{A Literacy that Matters: Storying as Artifactual}

Like artifacts, stories are embedded in daily lives (Pahl \& Rowsell, 2010), reveal individuals' ways of living and being (Hauf, 2010; LeCompte \& Ludwig, 2007), are preserved through being told and retold (Pahl \& Rowsell, 2010), and humanize our conditions. Therefore, I posit that stories are indeed artifacts because they exist as archives of individuals' ways of living and being and their personal and cultural histories (Lee, 2012). Sometimes these narratives reflect histories of oppression and silencing 
that individuals have faced, how they have resisted (Collins, 1991) and talked back to others, and ways in which they have achieved agency over their voices and bodies (Tong \& Botts, 2014).

How the women's stories in this study can be considered artifacts (Pahl \& Rowsell, 2010) is discussed in the next subsections on stories' embeddedness, connected practices, and habitus.

\section{Embeddedness of Stories}

First, participants' stories were not separate from their current experiences or recalled only for the purposes of this research but were embedded in their daily lives. Chowsie's stories were internally embedded in her remembering of her experiences of physical silencing and had been told to others throughout the years, and they were externally embodied in structures she independently built on her property. K's stories were embedded in the script and image of her tattoo, which mediated the backstory of her pregnancy, the emotional silencing she experienced, her son's death, and how she had been able to use her tattoo as a springboard to talk with others about her experiences. They had also been embedded in her relationships as she attempted to tell others about her marriage and pregnancy difficulties. Rhonda's stories were embedded in her visceral remembering of her pregnancy loss and in her attempts to story her pregnancy loss and hospital experience with family and friends. Though she faced silencing as a pastoral spouse and through others ignoring her perspectives, she was able to use this silencing to strengthen her own stance before revoicing her experience and talking back in language that mocked her hospital experience.

\section{Artifactual Literacy Practices}

As artifacts, the women's stories shared in this research illustrated the connected literacy practices of journal- and letter-writing, oral retelling of stories, and composition of nonverbal texts. K's collage and letter written to her deceased son, as extended literacy practices, involved her choice of positive symbolic images of motherhood and use of emotive language to story her experiences. Rhonda's talk about her hospital artifacts and the letter she wrote to her lost child were literacy practices in which she powerfully located, named, and memorialized her experiences. Though Rhonda provided no written artifacts specifically for this research study, her prior literacy practice of writing to her child along with her storying revealed her habitus of using silencing as agency.

\section{Story Habitus}

As artifacts, each woman's stories helped to reveal her habitus (Pahl \& Rowsell, 2010), or ways of being and living her experiences. As ways of living and being were uncovered, the stories also revealed how each woman navigated issues she confronted related to others' comments or perspectives imposed on her body as a social and political space (Pitts, 2003; Woods, 2012). Chowsie's stories, for example, revealed her lived experience as a Caucasian woman living and thriving as a survivor despite the disparaging narrative society constructed for her as a woman living below the poverty line amidst challenging circumstances. K's stories as artifacts revealed her habitus of living as an African American woman from a working-class background who overcame challenges and asserted her voice over efforts to silence it. Her stories as artifacts also foregrounded K's lived reality as a survivor and woman who rose up and pressed on despite others' oppositions and detractions. Through the years, her tattoo continued to serve as an invitation for others to hear her stories and tell their own. Rhonda's stories powerfully brought to light her lived reality as a Caucasian woman situated in privilege but silenced because of her former position as a pastoral spouse who was also a pregnancy loss survivor and a woman who unashamedly talked back in different ways to those who sought to silence her story. 
The women were able to talk with others about their experiences, and their stories exemplified the kinds of tensions related to sociocultural and patriarchal pressures as others attempt to control women's bodies through physical force, through stereotypical narratives that minimize women's abilities to maintain independent lives, through coercive decision-making, and ultimately through silencing their stories and thus their perspectives. Through their linguistic habits or ways speaking about their lives, their storying created a sharing space through which a trajectory of hope flowed, gleaming vibrantly. Through the language, images, behaviors, and embodiments (Nieves, 2012) they used to story their experiences, the women showed their resilience and strength to move forward while honoring their past struggles and triumphs.

\section{Implications for Practice}

This research adds to the growing body of research on Women's Ways of Knowing and storying and suggests a need for additional research to understand more fully women's experiences in diverse cultures worldwide to capture a comprehensive view. I also recommend research on all adults' storying, men's as well as women's, to capture a full spectrum of life experiences and not lose sight of the reciprocity among individuals. As Freire (2004) suggests, "Just as it is a mistake to get stuck in the local, losing our vision of the whole, so also it is a mistake to waft above the whole, renouncing any reference to the local whence the whole has emerged" (p. 87). Thus, I envision exploring storying from a global perspective as well as a practice that can benefit different individuals who story in their own communities, schools, and homes.

With regard specifically to women's diverse experiences with trauma and tensions, the findings from this research have broad implications, one of which is to attend to alternative forms and novel elements of storying. To deeply understand the histories of others' struggles (Anzaldua, 1990), we must go beyond just listening to their narratives and, as Pahl and Rowsell (2010) argue, take notice of the artifacts that are embedded in them, especially in stories of tensions and opposition that have directly impacted their lives. For example, I argue that adult learners' bodily artifacts are embedded in their stories and need to be more carefully understood and honored.

\section{Recommendations for Further Research}

This study's goal was to investigate how women from diverse backgrounds used storying as a space to make sense of their critical experiences with silencing, resistance/talking back, and resilience. The data collected to address this question were both narrative and artifactual. Though the results are meaningful, there are some limitations. Firstly, I had known the participants for many years as kin, friend, and/or fellow church member, which might have affected data collection and interpretation. On the other hand, my longstanding friendship with each of the women could have enhanced my position as a trusted listener and encouraged her to share to the degree that she did, thereby enriching the data. Secondly, this study was not longitudinal, and the established timeline allowed for capturing only a small segment of the participants' storying. Lastly, I had insider knowledge of many of the tensions that emerged in the women's storying, which caused me to not fully distance myself from the research, but again, this position allowed me privilege as an insider.

Longitudinal studies related to women's storying could allow more varied data to be collected that might reveal how stories evolve over time. Future studies might also explore the critical experiences of women in different age groups, such as female adolescents, whose storying connected to trauma or harsh experiences is not always welcomed in the classroom or other public settings. 


\section{Conclusion}

This research has confirmed that women use storying as a space to make sense of their crucial experiences, specifically with their experiences of being silenced, and ways in which they have resisted/talked back to others' silencing and have become resilient to rise up from their oppressive experiences. The women in this study were able to narrate their experiences of survival and rising up, even amidst opposition, while confronting the others in their lives, societal and individual, who sought to silence their voices. Thus, the study adds to the growing body of knowledge of women's storying by affirming it as a literacy practice in its varying narrative modes and as artifactual in its preservation of meaningful markers of a life journey. It is the hope that this research helps bring this knowledge into further discussions within academia and the research community and ignite expanded inquiry on what women's storying is and does.

\section{Acknowledgements}

I would like to express my gratitude to my participants, whom I call Chowsie, $\mathrm{K}$, and Rhonda in this research study. Their wisdom and strength have forever shaped who I have become. I feel honored to have been able to restory their experiences.

I would like to dedicate this article to the memory of Chowsie.

\section{Disclosure Statement}

All affiliations are listed on the title page of the manuscript, and there are no funding sources to be acknowledged for the research study from which this article emerged. There are no financial interests, including financial holdings, professional affiliations, advisory positions, board memberships, or receipt of consulting fees that could affect or have the perception of affecting the author's objectivity, or could influence or have the perception of influencing the content of the article. The author has no financial interest to declare.

\section{References}

Alcoff, L. (1988). Cultural feminism versus post-structuralism: The identity crisis in feminist theory. Anzaldua, G. (1990). La conciencia de la mestiza: Towards a new consciousness. In G. Anzaldua (Ed.), Making face, making soul/ Haciendo caras: Creative and critical perspectives by feminists of color (377402). Aunt Lute Books.

Bakhtin, M. (1981). The dialogic imagination: Four essays by MM Bakhtin. 1981. Speech genres and other late essays. Austin: University of Texas Press.

Bartky, S. L. (1996). The pedagogy of shame. In C. Luke (Ed.), Feminisms and pedagogies of everyday life (225-241). State University of New York Press.

Barton, D. (2001). Directions for literacy research: Analyzing language and social practices in a textually mediated world. Language and Education, 15(2-3), 92-104.

Barton, D., and Hamilton, M. (2000). Literary practices. In D. Barton, M. Hamilton, \& R. Ivanic (Eds.), Situated literacies: Reading and writing in context. Routledge.

Belenky, M., Clinchy, B., Goldberger, N., and Tarule, J. (1986). Women's ways of knowing: The development of self, voice, and mind. Basic Books.

Brown, C. (2013). Women's narratives of trauma: (Re)storying uncertainty, minimization and selfblame. Narrative Works, 3(1). Retrieved from https://journals.lib.unb.ca/index.php/NW/article/view/21063/24305 
Bye, C. (2005). I like to hoe my own row. Frontiers: A Journal of Women Studies, 26(3), 135-167.

Carbado D., Crenshaw, K.W., Mays, V.M., and Tomlinson, B. (2013). Intersectionality: Mapping the movements of a theory. Du Bois Review: Social Science Research on Race, 10(2), 303-312. Retrieved from http://doi.org/10.1017/S1742058X13000349.

Carlassare, E. (2009). Destabilizing the criticism of essentialism in ecofeminist discourse. Capitalism Nature Socialism, 50-66.

Cazden, C., Cope, B., Fairclough, N., Gee, J., Kalantzis, M., Kress, G., \& Nakata, M. (1996). New London Group. A pedagogy of multiliteracies: Designing social futures.” Harvard Educational Review, 66, 60-92.

Charmaz, K. (2014). Constructing grounded theory: A Practical guide through qualitative analysis (2nd ed.). SAGE.

Clarke, A. (2005). Situational analysis: Grounded theory after the post-modern turn. SAGE.

Collins, P. (1991). Black feminist thought: Knowledge, consciousness, and the politics of empowerment. Routledge.

Daniell, B. (2003). A communion of friendship: Literacy, spiritual practice, and women in recovery. Southern Illinois University Press.

Daiute, C. (2014). Narrative inquiry: A dynamic approach. SAGE.

Dillard, C. (2012). Learning to (re)member the things we've learned to forget: Endarkened feminisms, spirituality, and the sacred nature of research and teaching. Peter Lang Publishing.

Evans, S. (2003). Tidal wave: How women changed America at century's end. Free Press.

Fairclough, N. (2001). Language and power. Pearson Education.

Fernandes, L. (2010). Unsettling "Third Wave" in N. Hewitt (Ed.), No Permanent Waves: Recasting Histories of U.S. (98-120). New Brunswick, N.J.: Rutgers University Press.

Fisher, J. A. (2002). Tattooing the body, marking culture. Body \& Society, 8(4), 91-107.

Freire, P. (2004). Pedagogy of hope: Reliving pedagogy of the oppressed. Continuum.

Galvan, R. (2006). Campesina epistemologies and pedagogies of the spirit: Examining women's sobrevivencia. In D. Bernal, C. Elenes, F. Godinez, and S. Villenas (Eds.), Chicana/Latina education in everyday life: Feminista perspectives on pedagogy and epistemology (161-179). State University of New York Press.

García, A., \& Gaddes, A. (2012). Weaving language and culture: Latina adolescent writers in an afterschool writing project. Reading \& Writing Quarterly, 28(2), 143-163. Gee, J. P. (1998). What is literacy? Negotiating academic literacies: Teaching and learning across languages and cultures, 51-59.

Gilman, C. P. (1892). The yellow wallpaper. Retrieved from https://repositorio.ufsc.br/bitstream/handle/123456789/132727/The Yellow Wallpaper_( Charlotte Gilman 1892).pdf?sequence $=1$

Goldberger, N. (1996). Cultural imperatives and diversity in ways of knowing. In N. Goldberger, J. Tarule, B. Clinchy, and M. Belenky (Eds.), Knowledge, difference, and power: Essays inspired by women's ways of knowing (335-371). BasicBooks.

Goldberger, N., Tarule, J., Clinchy, B., \& Belenky, M. (Eds.). Knowledge, difference, and power: Essays inspired by women's ways of knowing. BasicBooks.

Gonzalez, F. (2006). Youth bodies and emerging subjectivities. In D. Bernal, C. Elenes, F. Godinez, and S. Villenas (Eds.), Chicana/Latina education in everyday life: Feminista perspectives on pedagogy and epistemology (pp. 11-13). State University of New York Press.

Gonzalez, N., Moll, L., and Amanti, C. (2005). Funds of knowledge: Theorizing practices in households, communities, and classrooms. Routledge.

Hardy, S., and Kukla, R. (2015). Making sense of miscarriage online. Journal of Social Philosophy, 46(1), 106-125. 
Hauf, J. (2010). Teaching world cultures through artifacts. Journal of Geography, 109(3), 113-123, DOI: 10.1080/00221341.2010.485261.

Heath, S. B. (1983). Ways with words: Language, life, and work in communities and classrooms. Cambridge University Press.

Heath, S. B. (1990). The fourth vision: Literate language at work. In A. A. Lunsford, H. Moglen, and J. Slevin (Eds.), The right to literacy (pp. 289-306). MLA.

hooks, b. (1990). Talking back. In G. Anzaldua (Ed.), Making face, making soul/Haciendo caras: Creative and critical perspectives by feminists of color (207-211). Aunt Lute Books.

hooks, b. (2015). Feminism is for everybody. South End Press.

Horne, J., Knox, D., Zusman, J., \& Zusman, M. E. (2007). Tattoos and piercings: Attitudes, behaviors, and interpretations of college students. College Student Journal, 41(4), 1011-1021.

Houston, M., and Kramarae, C. (1991). Speaking from silence: Methods of silencing and of resistance. Discourse \& Society, 2(4), 387-399.

Jones, S. (2006). Girls, social class, and literacy. Heinemann.

Kern, R. (2000). Literacy and language teaching. Oxford University Press.

Kidd, S. (1996). The dance of the dissident daughter. HarperCollins.

Kirkland, D. (2013). A search past silence: The literacy of young Black men. Teachers College Press/Columbia University.

Lather, P. (1992). Critical frames in educational research: Feminist and post-structural perspectives. Theory Into Practice, 31(2), 87-99.

Lather, P., and Smithies, C. (1997). Troubling the angels: Women living with HIV/AIDS. Westview Press.

Leader, K. (2015). Stories on the skin: Tattoo culture at a South Florida university. Arts \& Humanities in Higher Education, 14(4), 426-446.

LeCompte, M. D., \& Ludwig, S. A. (2007). I am my identity kit: Using artifact data in research on identity. EMIGRA Working Papers, 111, 1-16.

Lee, W. (2012). Never merely "there": Tattooing as a practice of writing and a telling of stories. In F. Alhoff (Ed.), Tattoos: Philosophy for everyone: I ink, therefore I am (151-164). Wiley-Blackwell.

Longino, H. (1994). In search of feminist epistemology. The Monist, 77(4), 472-485.

Lorde, A. (1977). The transformation of silence into language and action. In A. Lourde, Sister outsider: Essays and speeches (pp. 81-84). Crossing Press.

Luke, C. (1994). Women in the academy: The politics of speech and silence. British Journal of Sociology of Education, 15(2), 211-230.

Mackay, F. (2013). WTAF is intersectionality? Gaze: A Modern Review, 1, n.p.

Maddrell, A. (2013). Living with the deceased: Absence, presence, and absence-presence. Cultural Geographies, 20(4), 501-522.

McGill, C. (2011). 12 (Corner) stones: A model for literacy, empowerment, and development. In M. Miller and K. King (Eds.), Our stories, ourselves: The embodiment of women's learning in literacy (6167). Information Age Publishing, Inc.

Miller, M., \& King, K. (2011). Our stories, ourselves: The embodiment of women's learning in literacy. Information Age Publishing.

Minh-ha, T. (1990). Not you/like you: Post-colonial women and the interlocking questions of identity \& difference. In G. Anzaldua (Ed.), Making face, making soul/ Haciendo caras: Creative and critical perspectives by feminists of color (371-375). Aunt Lute Books.

Moll, L. (2000). Inspired by Vygotsky: Ethnographic experiments in education. In C. D. Lee \& P. Smagorisky (Eds.), Vygotskian perspectives on literacy research (pp. 256-268). Cambridge University Press.

Nieves, Y. (2012). Embodying Women's Stories for Community Awareness and Social Action. New Directions for Adult and Continuing Education, 134, 33-42. 
Otte, M. (2007). The mourning after: Languages of loss and grief in post-Katrina New Orleans. The Journal of American History, 94(3), 828-836.

Pahl, K., and Rowsell, J. (2010). Artifactual literacies: Every object tells a story. Teachers College Press.

Patil, V. (2013). From patriarchy to intersectionality: A transnational feminist assessment of how far we've really come. Signs: Journal of Women in Culture and Society, 38(4), 847-867.

Pitts, V. (2003). In the flesh: The cultural politics of body modification. Palgrave Macmillan.

Scribner, S., and Cole, M. (1978). Literacy without schooling: Testing for intellectual effects. Harvard Educational Review, 48(4), 448-461.

Seidman, I. (2013). Interviewing as qualitative research: A guide for researchers in education and the social sciences. Teachers College Press.

Shields, S. A. (2008). Gender: An intersectionality perspective. Sex Roles, 59(5-6), 301-311.

Stengle, P. (2003). Women, empowerment, and tattoos. (Unpublished doctoral dissertation). University of South Florida, St. Petersburg.

Stewart, A. (1994). Toward a feminist strategy for studying women's lives. In C. Franz \& A. Stewart (Eds.), Women creating lives: Identities, resilience, and resistance (11-35). Westview Press.

Symington, A. (2004). Intersectionality: A tool for gender and economic justice. Women's Rights and Economic Change, 9, 1-8.

Talvi, S. (2000). Marked for life: Tattoos and the redefinition of self. In O. Edut (Ed.), Body outlaws: Young women write about body image and identity (211-218). Seal Press.

Thiel-Stern, S., Hains, R., \& Mazzarella, S. (2011). Growing up white and female during the American Great Depression: Popular communication, media, and memory. Women's Studies in Communication, 34, 161-182.

Putnam Tong, R. (1998). Feminist thought: A more comprehensive introduction. NSW Australia Allen \& Unwin.

Tong, R., and Botts, T. (2014). Women of color feminisms. In R. Tong (Ed.), Feminist thought: A more comprehensive introduction (211-254). Westview Press.

Urban Dictionary (1999-2020). "Jaded." Retrieved from https://www.urbandictionary.com/define.php?term=The \%20Urban $\% 20$ Dictionary.

Uttal, L. (1990). Nods that silence. In G. Anzaldua (Ed.), Making face, making soul/ Haciendo caras: Creative and critical perspectives by feminists of color (317-320). Aunt Lute Books.

Vygotsky, L. S. (1997). The collected works of LS Vygotsky: Problems of the theory and history of psychology (Vol. 3). Springer Science \& Business Media.

Wohlrab, S., Stahl, J., \& Kappeler, P. M. (2007). Modifying the body: Motivations for getting tattooed and pierced. Body Image, 4(1), 87-95.

Woods, S. (2012). Writing on the body: The modern morality of the tattoo. In F. Allhoff (Ed.), Tattoos: Philosophy for everyone: I ink, therefore I am (pp. 206-217). Wiley-Blackwell. 